\title{
THE DEAD PARROT: DOES PROFESSIONAL SELF-REGULATION EXHIBIT VITAL SIGNS?
}

\author{
H.W. ARTHURS ${ }^{*}$
}

Self-governance of the legal profession, and the promulgation and enforcement of a code of professional conduct are usually justified by arguments from principle, practicality and past practice. None of these can be sustained. However, if professional self-governance were replaced by governmental or judicial regulation, the operational norms of professional conduct - the way lawyers actually behave - would likely not change very much. In fact, formal regulation, by whatever means, is not a major determinant of conduct that can be characterized as unethical. Rather, such conduct is largely determined by the personal characteristics of the individual lawyer, the professional circumstances of her or his practice, and especially the "ethical economy" of the profession. The "ethical economy" encompasses the social, political, economic and cultural forces, inside and outside the profession, which help to define which conduct will be treated as deviant or unethical and to identify who will be sanctioned for engaging in such conduct.
L'auto-gestion du barreau, la promulgation et le respect d'un code de conduite professionnelle, se justifie en général par des arguments invoquant les principes, des impératifs pratiques et la pratique passée. Aucun d'eux ne peut être fondé. Cependant, si l'auto-gestion professionnelle était remplacée par un règlement judiciaire ou gouvernemental, les normes fonctionnelles de conduite professionnelle la façon dont les avocats se conduisent véritablement - changeraient probablement très peu. En fait, tout règlement officiel, quel qu'il soit, ne permet pas vraiment de déterminer les conduites qualifiables de contraire à l'éthique. En fait, une telle conduite se détermine largement par les caractéristiques personnelles de chaque membre du barreau, les circonstances de sa pratique et surtout l'uéconomie éthique" de la profession. Cette économie englobe des forces sociales, politiques, économiques et culturelles, internes et externes, qui aident $\dot{a}$ définir les conduites aberrantes ou contraires à l'éthique et à reconnaitre qui sera passible de sanction.

\section{TABLE OF CONTENTS}

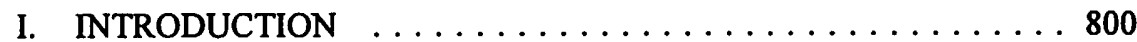

II. THE DETERMINANTS OF PROFESSIONAL CONDUCT: THE ETHICAL ECONOMY OF THE PROFESSION . . . . 802

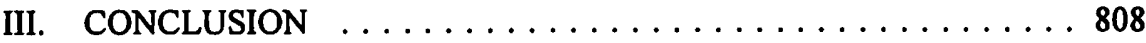

\section{INTRODUCTION}

Some of you will know the famous Monty Python skit in which a dissatisfied customer attempts to return a parrot to a pet shop on the relatively straightforward ground that it was dead when he bought it half an hour earlier. The clerk in the pet shop first tries evasive tactics: "look at its plumage," he says. Then he confronts the issue head on: "this parrot," he says, "is not dead; it's resting; it's shagged out after a

Professor of Law at Osgoode Hall Law School and President Emeritus of York University. He has served as Bencher of the Law Society of Upper Canada, a member of the 1974 Canadian Bar Association Committee to Revise the Code of Professional Responsibility, a member of the Economic Council of Canada, and President of the Canadian Civil Liberties Association. He has written extensively about the legal profession, legal education and legal history and theory, as well as labour law, administrative law and university planning and administration. His last major book was "Without the Law": Administrative Justice and Legal Pluralism in Nineteenth Century England (Toronto: University of Toronto Press, 1985). 
long squawk, it's kipping on its back." A vigorous debate ensues which - for Python aficionados - sounds very much like the debate over whether self-governance and codes of professional conduct are essential features of professional regulation.

We have all been through this debate; some of us can recite it with the same relish as we recite the dead parrot skit. First, there is the argument from principle: selfgoverning professions are needed to defend society against the all-pervasive power of the state. An autonomous bar, as the argument runs, is a sort of extrusion of an independent judiciary, which, in turn, is an indispensable adjunct of the rule of law. Secondly, there is the argument from practicality: professions must be self-governing because they alone understand what their members need to know, how they ought to behave, what constitutes deviant conduct, and which sanctions ought to be imposed when. And thirdly, there is the argument from past practice: professions ought to be self-governing because they have always been self-governing, as a result of which selfgovernance has become the distinguishing characteristic of a profession, as opposed to a "mere" trade or business.

I am unsure of the collective noun for these parrots, so I will have to administer last rites to each of them individually.

First, the argument from principle: there are all sorts of liberal, pluralistic democracies - Sweden comes to mind immediately - where the bar is not selfgoverning; there have been many times in our own Anglo-Canadian history when the bar and the bench were much more closely aligned with the forces of repression than with those of freedom; and some of our finest judges have come not from the selfgoverning wing of the profession, but from employment in government or universities. Practice does not confirm the principle.

Secondly, the argument from practicality: it is certainly true that lawyers know more about how law is practiced than anyone else; it is even arguable that this knowledge qualifies them to enforce standards of practice. But it does not follow that, because the profession has the power and the knowledge to regulate effectively, it will do so. The evidence is to the contrary: law societies have exhibited an invincible repugnance to the idea that they should use their knowledge and power to discipline incompetent lawyers, the very group that professional self-government is designed to suppress. The argument from practicality, I am afraid, will persuade no one but ourselves.

And finally, we come to the argument from precedent: since the bar and other professions have "always" been self-governing, any dilution of self-governance undermines their claim to be a profession. We are because we are because we are. The argument is circular: geometrically perfect but not historically perfect. What an American sociologist referred to as "the professionalization of almost everyone" is a process which began in the early nineteenth century, and continues unabated. In effect, occupational groups for almost two hundred years have been inflating their claims to knowledge in order to assert their "right" to respect and autonomy, to bid up the value of their intellectual and cultural capital, to control the market for their services and to enhance their financial and psychological rewards. 
Over the long haul, the bar has succeeded more often than not in defending its monopoly despite the problematic and precarious nature of its knowledge base. Nonetheless, there has been nothing fixed about the boundaries of our knowledge, the limits of our monopoly, or the autonomous character of our institutions of governance. Over time, each has changed considerably. Thus, to insist at any given moment that a particular constellation of institutional arrangements describes a profession - or even our profession - is to confuse description with prescription.

At a minimum, then, heroic measures - and possibly divine intervention - will be needed to breathe life into these parrots. We are going to have to come up with better arguments if we want to make the case that self-governance is essential to the maintenance of high professional standards.

\section{THE DETERMINANTS OF PROFESSIONAL CONDUCT: THE ETHICAL ECONOMY OF THE PROFESSION}

Let me now approach the issues the other way 'round. Would it really matter if we were to abandon the idea of professional self-regulation and hand over powers of discipline and disbarment to the courts or a regulatory agency? Not very much at all, I would argue. Essentially, much of what now passes for norms of professional conduct is a dead letter anyway, in terms of enforcement. Many, if not most, of the chapters of the Canadian Bar Association ("CBA") Code 1 are not in fact used to disbar or discipline lawyers. I personally would be pleased to hear that someone had been suspended for not representing clients resolutely, not adhering to high standards in the discharge of public office or not trying to improve the administration of justice. I would be delighted to know that someone who was discourteous to members of the profession or derelict in his or her duty to make legal services available to the public had attracted professional censure. But alas, such professional norms are violated with virtual impunity.

Essentially, lawyers in Canada are subject to serious discipline for just four reasons: because they have been guilty of theft, fraud, forgery or other some other criminal offence; because they have violated a fiduciary duty imposed on them by law; because they are unable to carry on their practices due to physical or mental disability or serious addiction; or because they have failed to respond to inquiries from their governing body.

Suppose there were no system of professional discipline: how would we handle these difficult matters? The first category - criminal fraud and related matters - is by far the most important statistically; all such matters could be, and now generally are, handled by courts of criminal jurisdiction. The second category - breaches of fiduciary duty - could likewise be competently handled by courts of civil jurisdiction. The steady but modest stream of cases involving personal and professional disability, I accept, would have to be handled in a specialized forum of some kind - if not the 
Law Society, then a body invented for the purpose. And as for the remaining, somewhat Orwellian, offence of failing to cooperate with the Law Society, perhaps we could get along without it.

Let me sum up my argument thus far in the form of two propositions: (1) much of the normative content of our Code of Professional Conduct never becomes operational because no regulatory effort is invested in its enforcement, and (2) much of what actually is operational in the Code could be enforced otherwise than by self-governing professional bodies. To these two propositions, I am now going to add a third: it does not matter very much who has the power to regulate the professions because, in fact, regulation is not a major determinant of professional conduct.

I want to acknowledge immediately that this proposition sits right in the middle of an ongoing emotional public debate about the use of penal sanctions to fight crime, sexism or pollution. Saying that fraud by lawyers is deterred by the Code of Professional Conduct and the risk of disbarment is like saying that Criminal Code amendments and lengthy jail terms will reduce the incidence of child abuse and armed robbery. If you believe one statement, you will believe the other; I am deeply agnostic about both.

Obviously, some importance does attach to the existence of a professional code backed, at least in theory, by serious sanctions. But I do not believe that prospective violaters embark upon a careful scrutiny of the code or a calculus of possible consequences before deciding to commit fraud or to tender perjured evidence.

To the contrary: if you want to know who is likely to misbehave, how and why, if you want to know how to prevent misbehaviour, if you want to know which standards of professional behaviour will be treated as worth enforcing and which will be ignored, there is little point in reading the Code of Professional Conduct or the reports of discipline proceedings. Professional conduct is, I believe, shaped by three important factors - the personal characteristics of the lawyer, the professional circumstances of his or her practice and the ethical economy of the profession. These parrots, I want to suggest, are very much in the land of the living. Let me invite each of them to squawk in turn.

People arrive at the study of law, and then at the practice of law, with intellectual endowments, psychological predispositions, family backgrounds, class, gender, racial and ethnic characteristics, educations, social experiences, coping skills, debts, ambitions and values. All of these qualities shape their behaviour as lawyers, just as they shape their behaviour in the rest of their lives.

Some of these same qualities also help to shape the circumstances in which they will practice. Generally speaking, aggressive people with superior intellectual skills who come from advantaged social backgrounds have a much better chance of practicing in elite firms than, say, those who are less ambitious, have poorer academic records or are black or female. Practicing in an elite firm, in turn, means that you will experience different pressures, confront different ethical concerns and be subject to a different kind 
of surveillance than, say, someone who practices in a suburban strip mall, a small town or a government department.

I do not want to leave the impression that lawyers in particular types of practices or locales are branded with a mark of original sin. However, the fact is that the legal profession, like the larger society it serves, is pretty highly stratified. Working conditions, support staff, collegial relations, control systems, capital investment, financial rewards, psychic pressures, public acclaim and personal satisfactions vary across sectors of the profession and over time. Ethical concerns likewise vary. Criminal lawyers seldom handle trust funds; commercial lawyers seldom deal in perjured testimony; tax counsel seldom find themselves in a conflict of interest; and conveyancers are seldom caught committing fraud at the top of the real estate market.

Finally, what I have elsewhere called the "ethical economy" of the legal profession explains which kinds of ethical concerns attract the vigilance of the Law Society, which are allowed to become a dead letter, and consequently, who is likely to find themselves in what kind of trouble.

For example, the proletariat of the profession - general practitioners - operate on thin profit margins and are sensitive to fluctuations in the demand for their services. If they have the political power to decide policy within the profession, if they are running the Law Society, they may well use that power to focus on policies which will stabilize the market for their services, such as limiting the annual intake into the profession, competitive advertising and the growing trend to specialization. Conversely, benchers who come from elite firms are more likely to focus on measures which reinforce their particular version of professional status and privilege. Since they handle large sums of money, they may well emphasize, say, policing measures which will reassure the public about lawyers' honesty. Since they offer sophisticated services to discerning and affluent clients, and can afford more training and the pursuit of higher credentials, they may favour compulsory examinations to achieve and enforce higher standards of competence.

I am not condemning either group. Understandably each will imagine that its version of lawyering is the norm, that its own interests exactly coincide with those of the profession and the public. However, there is a lot more to the politics of professional governance than self-delusion and self-aggrandizement. A great deal turns upon predominant understandings about the profession's long-term collective interests.

What collective interests? First example: autonomy is widely considered to be an important collective goal for the bar, a goal thought to be threatened by adverse publicity and a loss of public trust. Consequently, the profession tends to focus on those violations of the ethical code which are believed likely to undermine public trust and thus to threaten professional autonomy. Lawyers who cheat on their legal aid bills would fall into this category. To take another example, professional solidarity is thought by some to be an important factor in maintaining the profession's privileges. Consequently, lawyers who are perceived to undermine professional traditions of dignity and deference - individuals who are brash, for example, or who espouse 
radical views about the legal system - are liable to be the targets of disciplinary action.

My point is a simple one. The profession is not monolithic. It contains a number of sub-groups with interests, opinions, activities and styles which are not identical and indeed which are sometimes antagonistic. Which of these groups happens at any moment to control the definition and enforcement of the ethical code determines what kinds of offences are likely to be regarded as serious enough to be prosecuted. And since various offences are obviously more pertinent to some kinds of practices than to others, ultimately this means that whoever controls policy-making within the profession also effectively determines which types of lawyers will be regarded as creating discipline problems. Finally, since the demographics of different sectors within the profession vary considerably, discipline will ultimately fall unequally not only on different kinds of practitioners, but on members of different generations, classes, ethnicities, races and genders. That is what I mean by the "ethical economy" of the profession.

I hope no one imagines that I am saying anything controversial. Serious inequalities have been well-documented in family structures, schools and universities, the criminal justice system and the job market. Giving full credit to the bar for recent progress, and rumours of progress, it would be truly startling if perfect equality of opportunity or equality of respect existed within the legal profession itself. All I am saying is that these inequalities are reflected in the distribution of individuals amongst different sectors of practice, which are themselves sites of unequal degrees of temptation and instruments of control, and which are liable to be treated with unequal degrees of concern by those who generally preside over governing bodies and discipline committees.

Where does all this come to rest? Professional discipline is most often imposed on individuals who practice in small firms or alone. These individuals tend to be marginal in some way: in terms of their academic records, or their sociological or psychological profile. And periods of considerable disciplinary activity tend to track significant downturns in the economy, especially those involving a collapse of the real estate market. Recently, however, this familiar pattern has begun to change. In several highly publicized cases, lawyers in elite firms, until now seldom the target of professional discipline, have been found guilty of professional misconduct and even criminal activity. I would like to use this development to test my hypothesis about the three main determinants of professional conduct: personal characteristics, the context of the individual's practice situation and the ethical economy of the profession.

First, personal characteristics. In at least a few of these cases, the individuals involved were not main-line members of their particular elite firm. In some cases, they had joined the firm only recently; in some they were from backgrounds not well represented in the firm; in some their personal style marked them as somewhat deviant; one way or another, most could indeed be described as marginal within the setting of their firm. In other respects, however, they were actually typical members of the firm: the very characteristics which made them attractive recruits and high billers - their 
intelligence, hard work and aggressive character - were also the characteristics which enabled them to succeed in their misbehaviour, once they put their minds to it. Indeed, precisely because they were intelligent, hard working, aggressive and successful, their colleagues were probably reluctant at first to believe that they were acting improperly: they just did not fit the stereotype of the deviant lawyer.

This leads me to the next factor: the nature of practice in elite firms during the egregious eighties and the nasty nineties. Beginning in the sixties, and through to the end of the eighties, elite firms expanded rapidly in size and, through mergers and alliances, were able to dominate their particular client market more and more completely. This market is populated by corporate and institutional clients who require highly sophisticated, highly specialized and highly priced technical and strategic advice and representation.

The elite firms were able, more or less, to satisfy these requirements, but they had to transform themselves to do so. This is where they encountered difficulties. They became more capital and knowledge intensive, divided themselves into more highly specialized boutiques, and became more intimately involved in the business and political aspects of their clients' affairs. Because of financial pressures, they also became committed to a rate of expansion and diversification which exceeded the rate at which they could absorb new recruits into the firm's informal "culture," or handle new activities within existing protocols governing personnel practices, financial arrangements and firm management.

Thus, elite firms sometimes lacked either the formal structures or the informal understandings with which to control, coordinate and evaluate the loose aggregations of individuals practicing under the umbrella of the firm name. These shortcomings especially the decline of a strong firm culture - became evident during the economic crisis of the late eighties, when firm members came under terrific pressure to maintain the revenues needed to meet the financial obligations and expectations of partners, associates, employees, bankers and landlords. Under such pressure, marginal individuals were tempted or driven to take desperate measures and the customary intra-firm devices failed to deter or detect them. That, at least, is one hypothesis.

The other hypothesis - and I have to say it is equally tenable - is that misconduct of all kinds has always been as common in elite firms as elsewhere in the profession; what has changed is that it can no longer be concealed. This brings me to the third factor: the ethical economy of the profession.

I admit freely that what follows is very Ontario-centric, if that is not an oxymoron. However, let me advance the following proposition. Until ten or fifteen years ago the legal profession operated pretty much as a closed corporation. The governing body was dominated by lawyers from elite firms, abetted by leading counsel and members of the local gentry from around the province. Policy-making was largely tacit and discipline operated pretty much in secret. In such a context, the elite firms could count on being left to police themselves. They, in turn, held their members to standards which were at least as strict as those prevailing in the profession generally. When firm members 
occasionally committed defalcations or other forms of misconduct, the firm dealt with the offender and the offence on a confidential basis, rather than through the formal discipline procedures of the Law Society.

Now, however, the Law Society is run on a different basis. Increased stratification of the profession, demographic changes in the membership of the governing body, public pressure for more openness and accountability, improvement of accounting systems, increases in the sums being dealt with, greater aggressiveness by more sophisticated corporate clients, declining deference towards respected institutions across society: all these and other forces combined to ensure that the elite firms would be drawn more and more into the orbit of formal regulation, and once in that orbit, would no longer be treated in a privileged fashion.

In fact, the real significance of recent experience is this: the Law Society's handling of misbehaviour in elite firms came to be seen as the ultimate test of the profession's moral right to regulate itself. As a result of bad judgments by the firms themselves, delays in the discipline process, obfuscatory explanations and light penalties, the Law Society came near to failing this test, at least from a public point of view. From the point of view of the membership of the Society, these cases served both to illuminate and exacerbate tensions within the profession which were and are moving down fault lines of generation, geography and gender, of economics, politics and culture, and especially of knowledge, expertise and professional specialization.

I offer as a final example the crisis over competence now being experienced by the profession. As I have suggested, competence was essentially not on our agenda at all until the 1970s. In 1974, however, the CBA adopted its new Code of Professional Conduct which did indeed establish a "duty to be competent": ${ }^{2}$ does this not prove that such codes make a difference? Such a conclusion, I would argue, is a classic instance of the post hoc, propter hoc fallacy. The 1974 Code - and I was one of its authors was not the cause of a professional crisis over competence; it was an effect.

Causes have to be found elsewhere. The most obvious is the profession's experience with malpractice insurance. Partly as a referred result of rising malpractice claims in the United States, malpractice insurance became pretty much universal in Ontario during the 1960s. In the early 1970s, it became mandatory; and as soon as it became mandatory, the Law Society had to step in initially to define the terms of coverage, then to negotiate premiums and finally to act as a self-insurer. Thus, the governing body for the first time acquired a direct stake in the costs and consequences of incompetence.

For this reason, it had a strong motivation to contain rising costs, and this it did (as did other Law Societies) by attempting to reduce the incidence of claims. As premiums continued to escalate, various forms of intervention were proposed and instituted: improved educational programs, practice advisory services, mandatory continuing 
education, certification of specialists, mandatory re-certification of all lawyers and so forth.

Rising premium costs and rising levels of intervention by the Law Society in turn had an important effect on the behaviour of law firms.. Some of these were obvious and desirable: firms introduced new control systems to catch procedural lapses; subspecialties emerged within and amongst firms to ensure that appropriate levels of expertise were available in exotic areas of practice; in-firm training, education and research functions were expanded. Now, a second wave of effects is emerging: the cost of malpractice insurance is rising so sharply that it has begun to materially affect operating costs, profit levels and perhaps even the ability of small firms to survive. As a consequence, sectors of the bar which generate the least claims, such as criminal lawyers, are rebelling against having to pay premiums which, in effect, subsidize sectors such as conveyancing, which generate the most.

In other words, the new concern with competence has set in motion powerful economic and political forces within the profession. But these forces are virtually unconcerned with the 1974 changes in the Code of Professional Conduct. Indeed, the competence crisis has very little to do with any aspect of professional ethics. Rather, in my view, it results from profound changes in the nature of law as an intellectual discipline, as a profession and as a socio-economic and political phenomenon.

\section{CONCLUSION}

A few concluding notes, in no particular order: As law has become more and more the regulatory instrument of the interventionist state, it has become more detailed and complex. As it has become more detailed and more complex, the risks of error have grown exponentially. Further, it is not just law in the juridical sense which has changed. Many of the things lawyers are being called on to do involve an understanding of what lies underneath the rules, what is the social and political context of the rules, what likelihood there is of someone - including the client - securing a change in the rules, and what implications the rules have for the business interests or personal well-being of the client. The advice-giving function of lawyers has become infinitely more complex and so has the representational function, especially since the advent of the Charter. ${ }^{3}$ Again, opportunities for malpractice proliferate.

All of this means that the knowledge base of the contemporary lawyer must be both broader and deeper than that of previous generations but also that it must constantly be purged, renewed and expanded. This is particularly hard to accomplish since law has been slow in emerging as an intellectual discipline and still lacks a rigorous base of fundamental knowledge comparable to other social sciences, let alone the natural sciences. The absence of this knowledge base has led to the absence of standard texts built on agreed foundational assumptions, which in turn has led to the absence of standard procedures which might calibrate competence in particular fields of law. The 
absence of an agreed knowledge base is by no means entirely negative: it contributes to widely varied and far-ranging debate in legal academic discourse. However, it certainly does exacerbate the difficulty of preparing lawyers to deal with a rapidly changing and expanding body of legal knowledge in such a way as to minimize the risks of errors and of malpractice claims.

To restate and expand my fundamental point: the crisis of competence being experienced by the legal profession today is only marginally related to the 1974 changes in the Code of Professional Conduct, or to Law Society policies designed to enforce the new Code or to reduce malpractice claims through more training and testing. Rather, it is a reflection of fundamental changes in the very nature of law in our society, in the foundational understandings of legal intellectual work, and in our inability, so far, to address problematic aspects of our system of legal education and training.

To conclude with excerpts from the rich Pythonian lexicon: this parrot of selfregulation is definitely deceased; it is pushing up the daisies; it has joined the choir invisible; it is bereft of life; it has met its maker; it is no more; it is bleeding demised. 